\title{
Return to Azraq
}

\author{
J.B. Nelson
}

The author found many changes when he returned to Azraq after an absence of 14 years. Although the concept of a major Desert National Park had been abandoned, two reserves, embracing semi-desert and wetland, had been created. The Shaumari Reserve is having some success in breeding desert species for re-establishment in the wild, notably the oryx. The Wetland Reserve, however, is in danger; its wildfowl populations appear to be declining and the central marsh may be shrinking. Remedial action is essential if the wetland is to retain its importance, both as a reserve for birds and as a tourist attraction.

On 12 April 1983, and for the first time since 1969, when we used to live there (Nelson, 1973), I visited Azraq with Omar Rahmet of the Royal Society for the Conservation of Nature (RSCN) in Jordan. After the explosive despoilations, all over the world, of the late 1960s and 1970s, the old maxim, 'never go back' is truer than ever it was. In my own limited experience, and within this time span, the Galapagos has been opened up to tourism, the Peruvian seabird islands have lost most of their birds, Christmas Island has been ruined by phosphate mining, Aberdeen and its environs, where I lived, have been socially and in other ways disfigured by North Sea oil, and ... Azraq? Arzaq, although made famous by Lawrence of Arabia and visited by a few intrepid ornithologists, for example Colonel Richard Meinertzhagen, first became well known in 1965 through Guy Mountfort's Portrait of a Desert. At that time, the idea was to establish a major Desert National Park, but the massive subsequent developments have firmly cancelled that option. However, two smaller reserves-one of badia 22 (semi-desert) at Shaumari and the other embracing part of the wetland around the pools at South Azraq, have been established, and it is in the content of their future that I write.

The highway that now turns off the Zerka/Irbid road and crosses the desert to Azraq South, where it branches eastwards to Baghdad and south to Saudi Arabia, has drastically altered the whole area. Although it is truly an eyesore, the highway and the lorries in themselves need not seriously harm conservation interests. They generate gargantuan amounts of rubbish and there is obviously some air pollution, but these are not fundamental problems and the other pressures that have followed in the wake of the highway, such as the increase in numbers of houses, farms, businesses, hotels and visitors, can be ameliorated independently.

\section{Concern for wildfowl}

We went first to the old hunting lodge, which was used as a hospital in the First World War. It stands on a rise, below the old police post and overlooking the marsh. It was unchanged, and if I ignored the goliaths roaring down the highway to my left, where we used to meander across the stony slope to fetch milk from Ramon Said's farm, and treated various distant and hazy sprawls of buildings as mirages, I could have been watching the same swallows feeding around the dried dusty saplings, which seemed as small and hopeless as in 1969. The duck shooting season had ended 12 days before and the place was locked. Shooting is theoretically confined to Fridays and Sundays each week and Omar Rahmet is there on those days. There is concerm because the number of Oryx Vol 19 No 1 
wildfowl has dropped steadily since the 1960s, but this decline cannot have resulted from shooting (legally) too many - the season's official bag is far too small for that. Illegal shooting and disturbance on non-shooting days may well have driven many wildfowl to other feeding and resting areas, but perhaps more ominously still, the continuing reduction in the northern breeding areas of these wintering wildfowl may be steadily whittling down the population. If the Azraq area is to attract the maximum number of wildfowl it must be shot over and disturbed as little as possible. Finding sufficient food in winter, particularly for dabbling duck that need to work hard for long periods to take in enough small items, is not easy and every disturbance costs them time and energy and a reduced feeding rate for some considerable time afterwards. Artificial feeding may help, but grain is expensive and frequent disturbance may inhibit duck from using it to the full.

The single most important factor in attracting waterfowl is of course water. Man cannot control rainfall, and since the Azraq Qua fills largely from run-off, its size varies from year to year. In 1982, a good rain year, the Qua was vast and highly productive. Hundreds, perhaps thousands of tons of fish, up to several centimetres in length

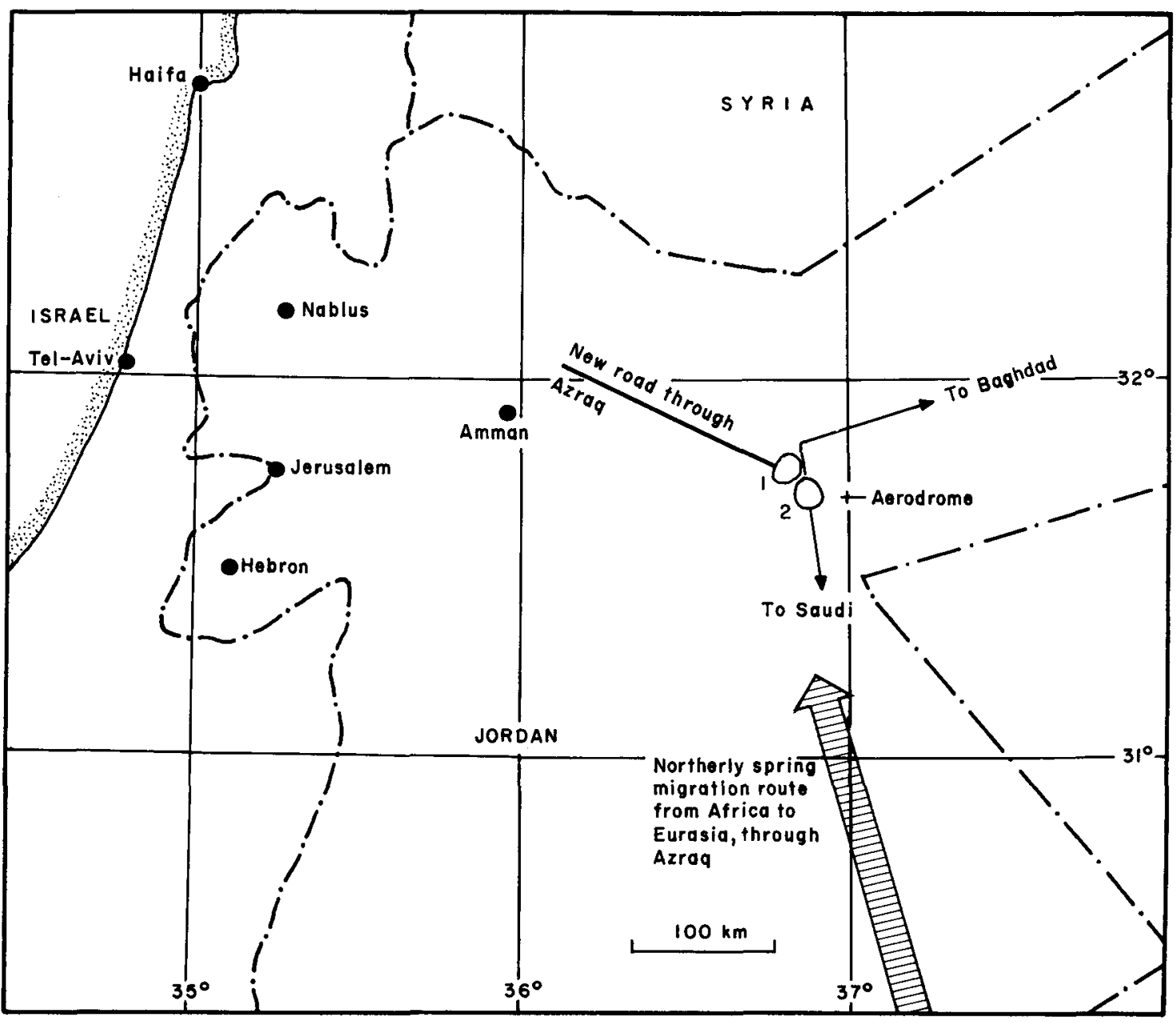

Map of Jordan showing location of (1) Azraq (Wetland Reserve), and (2) Shaumari Reserve, which is $7 \mathrm{~km}$ south-west of Azraq 
(probably Tilapia spp. though I did not see any) grew in a few weeks. But the central marsh, fed from the underlying aquifers, is, or should be, permanent. If the flow of water to the central marsh and to some of the surrounding areas (because some lagoons which grow seasonal crops of grasses and sedges are partly aquifer-fed) diminishes, the wildfowl habitat is reduced. Unfortunately, and despite every warning, the amount of water removed from the Azraq inflow and thus from the aquifers has greatly increased and is still increasing. This seems to be a matter more of expediency than necessity and, from the conservation and environmental point of view, nothing could be more damaging. One of my main aims had been to get a really good look at the central marsh and try to assess whether it had shrunk, for in the intervening years I had received disturbing local reports about it drying up. Alas, time ran out on me, but my superficial impression was undoubtedly that it had shrunk and that areas which should have been green with Typha angustifolia and Arundo donax were brown. We know approximately how much permanent marsh there should be, and it would seem a matter of urgency for somebody to spend a few days in establishing how much there now is. One of the universities in Jordan should be able to do this. It is essential ammunition in the conservation battle.

Our next stop was the Shaumari Reserve, an area of $22 \mathrm{sq} \mathrm{km}$ within which there are breeding pens and buildings suitable for laboratory work. Shaumari is, in a sense, the scaled-down Desert National Park and Desert Biological Research Centre combined. With considerable support from WWF and IUCN and generous donations from Saudi Arabia and Oman, the whole area (330 sq $\mathrm{km}$ ) has been fenced, an inner core fenced, and breeding pens with completely predator-proof mesh, established. The aim is to re-establish within the Azraq area some of the animals which have been shot out. The thriving herd of oryx numbered 30 at the time of our visit, including a four-day-old calf. All lexcept one bottle-reared male, imprinted on humans and intolerant of its own kind) were browsing amongst the greatly regenerated desert scrub and wild grasses. Known in Arabic as maha (the crystal) because of their white colour, they are indeed conspicuous (Omar told us that some Arabs call it al wedehi-the evident one) and impressive animals. Clearly, the area suits them and since I visited 31 have been released into the extensive natural habitat at Shaumari (Fitter, 1984). Only human persecution would seem to stand in the way of full liberation and if educational propaganda through the mass media can solve this problem the oryx has a future here.

At present there are 15 Arabian gazelles, including calves, outside the breeding pens at Shaumari. They have been less successful than the oryx; several calves have died and some adults injured. It seems that wild flights away from visitors, which apparently have flocked to Shaumari in large numbers, have led to injury. Visitors are now more strictly controlled and these shy and lovely animals were evidently at ease and able to put adequate distance between us and themselves. In the past, confinement within a too-small area has probably stressed them and when they are released into the full Shaumari Reserve (which will be soon) that problem should disappear. In particular, the greater area contains patches of hammada (bare, stony desert) which the inner core does not, and an experienced gazelle-hunter has advised the RSCN that females choose such places in which to drop their calves. It was delightful to see them resting and browsing amidst the aromatic scrub which has flourished since camels, goats and sheep were excluded. This success, incidentally, was quoted at a conference I attended in Amman and drew the fire of an Egyptian professor, who praised goats for turning scrub into milk and expressed the opinion that it is more important to feed people than to provide reserves for scorpions and rattlesnakes'. Apart from a minor point of rattlesnake distribution, he apparently overlooked the matter of sustainable pressure on an environment. Scrub can be turned into milk, but stones cannot.

Until recently Shaumari also held a pair of ostriches but the male sat on a sand adder (Cerastes sp.). It is hoped to obtain another male shortly, for it has long been hoped to reintroduce these great birds to the Azraq area. A pair of onagers (wild asses) are also settling down in one of the pens and may found a small herd. Whether the final phase, full liberation, ever occurs for all

Oryx Vol 19 No 1 


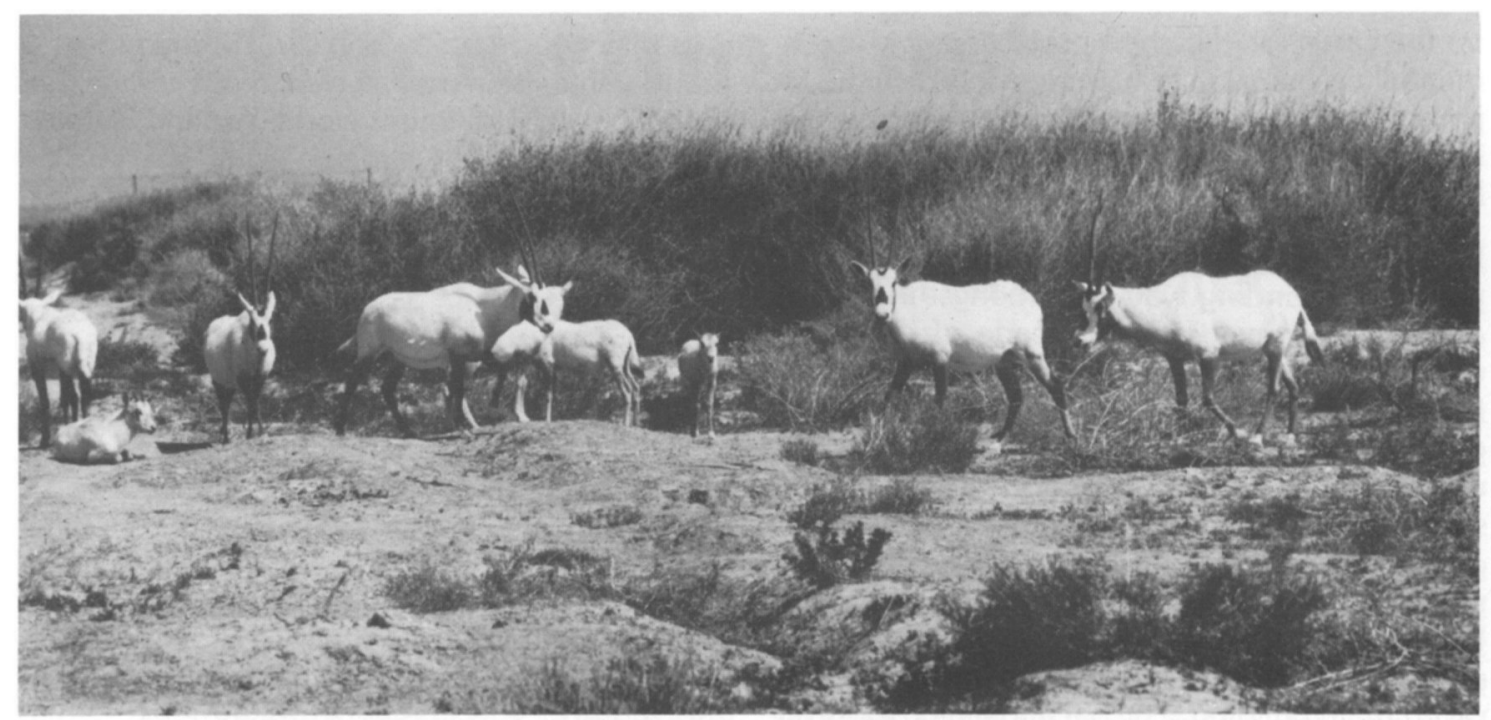

White or Arabian oryx at Shaumari Reserve (J.B. Nelson).

these species will probably depend on the RSCN's assessment of public support for their protection.

The fine cover at Shaumari attracts many migrants. Within a few yards of each other, and in lovely plumage, we saw woodchat, masked and lesser grey shrikes, hoopoes, pied wheatears, redrumped swallows and many others. Harriers, falcons, eagles and owls of several kinds constantly hunt here and the stream of Palaearctic migrants would keep the twitcher in a state of delinium tremens.

Beyond doubt the Shaumari Reserve is one of the most attractive places in the Middle East for desert-oriented research. It harbours a wealth of desert plants, insects, reptiles and birds and its semi-captive mammals offer great opportunities for the student of animal behaviour and for controlled grazing experiments. Teamwork between botanists, soil specialists, micro-climatologists and zoologists could produce valuable findings in applied ecology. There are the necessary facilities for a small group, which could consist of postgraduate students from Jordan and abroad, visiting academics on postdoctoral fellowships and sabbaticals, and Jordanians in permanent posts.

Shaumaii has improved since 1969. I wish that I could say the same for the village of Azraq South
(Shishan as it used to be called). I remembered a dusty village with sandy lanes between the houses and a tiny mosque against the background of the green marsh. Outside the shady cavern of the village shop two or three arabs used to sit on small wooden stools, drinking sweet tea. Now, the broad highway sweeps down the hill, past the police post where the famous Desert Police used to tether their racing camels, and rolls massively through the village. Strewn along its edge the shops, garages and resthouses sit amidst their own tide-line of boxes, torn tyres, broken exhausts and plastic bags. Enormous lorries rumble through, their drivers leaning down to buy the thin arab 'flag' bread displayed by vendors. The litter flows out on to the edge of the qua, where the tamarisk and Nitraria scrub becomes sparser and sparser. Litter festoons every bush, post, fence and anything robust enough to capture a windblown piece of torn plastic or a sheet of newspaper. Azraq North, by strange contrast, is incomparably cleaner. The road to Baghdad brushes my friend Hassan's house and sweeps past the old Roman castle but without its fringe of exhausts and shredded tyres. Azraq North is a Druze village and seems to possess a stronger pride and community spirit than its neighbour. Rubbish, of course, is a very superficial problem and the RSCN is well aware of it. A clean-up campaign and proper dumping pits are 
on the cards, but like bird-protection, it is fundamentally a question of attitudes. It takes time for parents and teachers to get the message and pass it down. After all, as our parking places show, we have still not got the message in Britain.

I remembered with affection the rusty old iron pipe that, standing way out amongst the basalt, delivered a never-failing cascade of deliciously warm, sulphurated water. It was bliss to soak in the rough cavity hollowed out beneath the flow. A government resthouse has now been built nearby with two swimming baths-one (near the hot spring) is large and shallow and the other (in the grounds of the resthouse) is large and deep. The resthouse is magnificent, but melancholy. It is built partly of hewn sione, with air-conditioned chalets adjacent to the well-proportioned, terraced main building. The bar and dining room are elegant and well furnished, the foyer spacious, but on this April day, admittedly early in the season and a weekday, the place was lifeless. Apart from one occupied table on the terrace, there was nobody. The swimming pool, which should be the central attraction, was as dry as the desert, its tiles broken (partly through faulty building) - new but virtually unused. The welldesigned children's playground, shaded by Eucalyptus trees, stood empty. Beyond, the shallow pool, which should have received the hot water from the sulphur spring, held only windblown rubbish, its flanking terraces lifeless. It seemed an enormous pity. Great effort and expense had been put into these ventures, but the heart of them should be the pools with their treeshaded terraces. If they functioned, surely this place would be a great attraction and would take pressure off the natural pools and the surrounding areas. The resthouse itself would make an ideal base for parties of birdwatchers that, nowadays, several specialised travel agencies organise. Probably few foreign tour-operators are even aware of its existence, let alone its excellence. Azraq is routinely included in Jordanian hand-outs as a place for birdwatching, but few (except ornithologists 'in the know') have any idea what the place is like, where to go, and where to stay. Superficially they may see only the highway, scattered buildings, and an empty qua. In reality, with Shaumari, the Wetland Reserve, and the government resthouse, there are all the mak- ings of a good birding holiday. On the fringes of the marsh, within a short walk of the village, one enters a totally different world. Around Burgess, and Inglesi in the evening light, the shallow lagoons were alive with birds. Shoveler, teal, wigeon, shelduck, garganey, stilts, green sandpipers, stints, sand-plovers, black terns, and many more that I had no time to follow up. Soon this Wetland Reserve, including some qua-edge, will be fully protected. The shooting blinds lie within the fence, but shooters are not allowed to enter the marsh proper. Providing that the water remains, Azraq's birds should remain also.

Everything has happened too rapidly at Azraq and the conflict between its various roles is painfully obvious: village communities, military base (there is an airfield here), farming, industry, trucking, nature conservation, wildfowling, family recreation-all of these have their special needs and to reconcile them will at times prove impossible. But the amazing thing is that so much coexistence is possible. At present, the various components have not settled into a harmonious pattern, but a reasonably optimistic view would see a flourishing research centre at Shaumari, including some projects from the Wetland Reserve and a spring and autumn influx of ornithologists to revel in the bird migration and provide custom for the resthouse. In summer there could be a steady flow of Jordanian families to the swimming pools and environs of the resthouse, in winter the activities of the wildfowlers, strictly regulated by the RSCN. A major attempt to present Azraq's conservation needs to the children in the Azraq schools and more generally in the media, together with attractive visual displays at the resthouse, Shaumari and the hunting lodge should eventually change attitudes for the better. Above all, strict attention to the waterflow and the state of the marsh is essential. It cannot be said too often that there is a point of no return in the depletion of the aquifers and the inflow to the marsh. Shaumari is safe, but the wetland is clearly on the danger list.

\section{References}

Fitter, R. 1984. Operation Oryx - the success continues. Oryx XVII, 136.

Mountfort, G. 1965. Portrait of a Desert. Collins, London. Nelson, J.B. 1973. Azraq: Desert Oasis. Allen Lane, London. Bryan Nelson, Balkirk, Glenlochar, Castle Douglas DG7 2LU, UK.

Oryx Vol 19 No 1 